\title{
Oxytocin deficiency at delivery with epidural analgesia
}

\author{
C. F. GOODFELLOW Department of Obstetrics and Gynaecology, University of Leeds, 17 \\ Springfield Mount, Leeds LS2 9NG, UK
}

M. G. R. HULL University Department of Obstetrics and Gynaecology, Bristol Maternity

Hospital, Southwell Street, Bristol BS2 8EG, UK

D. F. SWAAB, J. DOGTEROM \& R. M. BUIJS Netherlands Institute for Brain Research, Amsterdam

\begin{abstract}
Summary. The effect of epidural analgesia on oxytocin release during the second stage of normal labour was studied by comparing 10 primigravidae who had epidurals with 10 control subjects who did not have epidurals. A significant increment in oxytocin between paired peripheral blood samples taken at the onset of full cervical dilatation and crowning of the fetal head was found in the control subjects but not in those with epidurals. Forceps delivery was required more often in the group with epidural analgesia and was associated with lower oxytocin levels at crowning. Since distension of the lower birth canal and stimulation of pelvic autonomic nerves leads to oxytocin release, and the need for forceps associated with epidurals can be reduced by oxytocin, these differences are attributed to the lumbar epidural block.
\end{abstract}

During normal delivery stretching of the lower birth canal is thought to trigger a neurohumoral reflex leading to rapid secretion of oxytocin by the pituitary gland which results in strong 'expulsive' contractions (Fitzpatrick 1961). The reflex is well demonstrated in animal experiments (Debackere et al. 1961). In women stimulation of the presacral nerves, in which afferent autonomic neurons from the birth canal are conveyed, increases intrauterine pressure with a contraction (Alvarez et al. 1965). During the second stage of labour a marked increase in oxytocin activity in jugular vein plasma equivalent to $900 \mu$-units $/ \mathrm{ml}$ has been described (Coch et al. 1965). Dawood et al. (1978) reported increased peripheral blood levels of oxytocin during labour which reached a maximum in the second stage and Leake et al. (1979) found an increase in oxytocin with delivery of the fetal head.

Since there has been an increased need for forceps delivery associated with lumbar epidural analgesia in labour (Bristol Maternity Hospital Report 1976; Rotunda Hospital Clinical Report
1979; O'Driscoll \& Meagher 1980; Paintin \& Vincent 1980), we studied the effect on this reflex of blocking genital sensation by epidural analgesia. Controversy over the role of oxytocin as a possible initiator of labour (Swaab \& Boer 1979) has led some to dispute any physiological role at all for oxytocin in man; others attribute the association between forceps delivery and epidural analgesia to the attitudes of the attendant (Doughty 1969). Oxytocin in the circulation is difficult to study since only a small fraction of the jugular vein concentration is found peripherally (Coch et al. 1965); it is rapidly broken down by oxytocinase so rapid cooling of samples is essential to reduce enzyme activity (Kumaresan et al. 1974). Since oxytocinase activity varies greatly between individuals (Gazárek et al. 1976), individual changes in oxytocin levels were expected to provide more information than absolute levels and are the basis of this study.

\section{Patients and methods}

Normal primigravidae in normal labour between 37 and 41 weeks gestation were studied after their informed consent for venepuncture. Epidural 
analgesia was chosen before the study by half the subjects and was conducted as described previously (Goodfellow \& Studd 1979). The following criteria were met: epidural analgesia was effective in all receiving it and autonomic block was confirmed with the perianal scratch test when perineal sensation was present. Women not receiving epidural analgesia were given pethidine $(50-100 \mathrm{mg})$, Stemetil $(12.5 \mathrm{mg})$ and nitrous oxide/oxygen as required. None required acceleration of labour with oxytocin or prostaglandins as judged by a rate of cervical dilatation of $\geqslant 1 \mathrm{~cm} / \mathrm{h}$. No complications of labour occurred other than delay in the second stage in those who required forceps.

An antecubital venous blood sample was taken at the beginning and at the end of the second stage. The onset of the second stage was defined as full cervical dilatation without visible external signs. To avoid stimulating spurious oxytocin release by vaginal examination (Vasicka et al. 1978) the first sample was taken on a presumptive diagnosis without examination in the preceding hour. Only those patients were studied who were found to be fully dilated by routine vaginal examination or by the appearance of external signs within $15 \mathrm{~min}$ after sampling. The second sample was taken from the same vein in the same way at crowning of the fetal head or before any interference to aid operative delivery, including the injection of local anaesthetic for perineal and pudendal 'blocks' in the control subjects.

Blood samples $(5 \mathrm{ml})$ were collected with icecold plastic syringes, needles and lithium heparin containers, transported on ice and within $5 \mathrm{~min}$ spun at $1000 \mathrm{rev} . / \mathrm{min}$ for $10 \mathrm{~min}$ in a Mistral $2 \mathrm{~L}$ MSE refrigerated centrifuge precooled to $4^{\circ} \mathrm{C}$. The plasma was separated, flash frozen and stored immediately at or below $-20^{\circ} \mathrm{C}$. Samples from each patient were assayed in the same batch but were numbered randomly so that patients could not be identified in the laboratory. Oxytocin was determined by radioimmunoassay as described by Dogterom et al. $(1977,1980)$, within 8 months after collection. The intra-assay coefficient of variation for $16 \mathrm{pg}$ was $10 \cdot 17 \%$ $(n=20)$, and the interassay coefficient of variation for $32 \mathrm{pg}$ extracted from $1 \mathrm{ml}$ was $8.6 \%$ $(n=21)$.

\section{Statistical methods}

Statistical analysis of both cross-sectional and paired-sample observations was carried out by non-parametric tests since parametric tests were sometimes inappropriate to distribution. Pearson's linear correlation coefficient $r$, the Mann-Whitney $U$-test, Spearman's coefficient of rank correlation $r_{\mathrm{S}}$ and Fisher's exact test were computed. Where it is stated that no significant change was found $P$ was $>0 \cdot 1$.

\section{Results}

Twenty women were studied, 10 had epidural analgesia and 10 were control subjects. Their clinical details are given in Table 1 together with the oxytocin concentrations and increments (crowning-full dilatation concentrations) which are shown in relation to the mode of delivery and use of analgesia in Fig. 1.

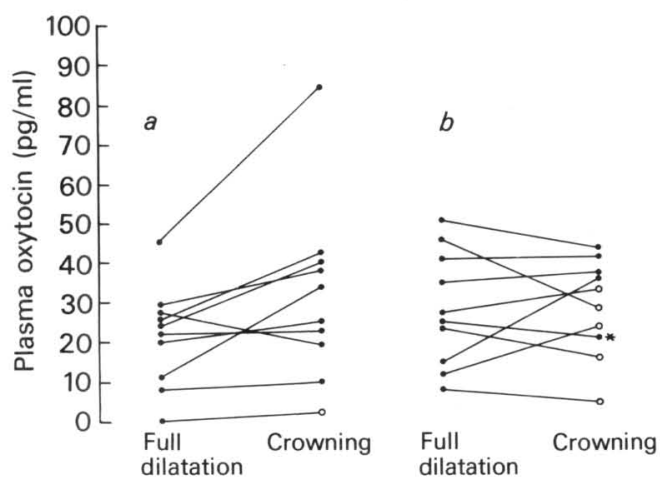

Fig. 1. Oxytocin levels in the second stage of control (a) and epidural (b) groups related to mode of delivery. $O$, Forceps delivery.

* Generous episiotomy and strong fundal pressure with persistent occiput posterior position.

There were no significant differences between the mean age, height, weight (at last antenatal visit) or duration of the first stage of labour in the two groups. There was no significant relation in individual subjects (see end of Results section) between any of these features and the levels of oxytocin or the increment during the second stage of labour.

There were no significant differences in oxytocin levels between control and epidural groups at the onset of the second stage or at crowning; comparison of paired data, however, revealed an increment in 9 out of 10 control subjects but in only 5 of the 10 patients with epidural analgesia (Fig. 1).

There was a significant rise in oxytocin levels in the control group [mean increment $10 \cdot 1 \mathrm{pg} / \mathrm{ml}$ 
Table 1. Clinical details and plasma oxytocin concentrations at the beginning and end of the second stage of labour in the 20 patients studied (all normal primigravidae)

Plasma oxytocin concn (pg/ml)

\begin{tabular}{|c|c|c|c|c|c|c|c|c|c|}
\hline \multirow[b]{2}{*}{$\begin{array}{l}\text { Patient } \\
\text { no. }\end{array}$} & \multirow[b]{2}{*}{ Delivery } & \multirow[b]{2}{*}{$\begin{array}{c}\text { Age } \\
\text { (years) }\end{array}$} & \multirow[b]{2}{*}{$\begin{array}{l}\text { Height } \\
\text { (m) }\end{array}$} & \multirow[b]{2}{*}{$\begin{array}{l}\text { Weight } \\
\text { (kg) }\end{array}$} & \multirow[b]{2}{*}{$\begin{array}{l}\text { Birth- } \\
\text { weight } \\
(\mathrm{kg})\end{array}$} & \multirow[b]{2}{*}{$\begin{array}{l}\text { Duration of } \\
\text { 1st stage } \\
\text { (h) }\end{array}$} & \multicolumn{3}{|c|}{ Plasma oxytocin conen (pg/ml) } \\
\hline & & & & & & & $\begin{array}{c}\text { At full } \\
\text { dilatation }\end{array}$ & $\begin{array}{c}\text { At } \\
\text { crowning }\end{array}$ & Increment $^{a}$ \\
\hline \multicolumn{10}{|c|}{ Control group } \\
\hline 1 & $\mathrm{~S}$ & 31 & $1 \cdot 70$ & $74 \cdot 5$ & $3 \cdot 760$ & $2 \cdot 75$ & $46 \cdot 0$ & $85 \cdot 0$ & $+39 \cdot 0$ \\
\hline 2 & $\mathrm{~S}$ & 25 & 1.51 & $41 \cdot 6$ & $3 \cdot 370$ & $7 \cdot 75$ & $11 \cdot 6$ & $34 \cdot 2$ & $+22 \cdot 6$ \\
\hline 3 & $S$ & 26 & $1 \cdot 66$ & $85 \cdot 5$ & $3 \cdot 960$ & $3 \cdot 50$ & $26 \cdot 0$ & $42 \cdot 0$ & $+16 \cdot 0$ \\
\hline 4 & S & 22 & 1.57 & $54 \cdot 6$ & $3 \cdot 480$ & $5 \cdot 75$ & $25 \cdot 8$ & $40 \cdot 4$ & $+14 \cdot 6$ \\
\hline 5 & S & 24 & 1.62 & $56 \cdot 3$ & $2 \cdot 870$ & $10 \cdot 25$ & 29.4 & $38 \cdot 9$ & +9.5 \\
\hline 6 & S & 27 & 1.57 & $52 \cdot 5$ & $2 \cdot 500$ & 6.00 & 21.0 & $25 \cdot 0$ & $+4 \cdot 0$ \\
\hline 7 & F & 18 & 1.73 & $66 \cdot 3$ & 4.950 & $6 \cdot 50$ & $7 \cdot 2$ & $2 \cdot 29$ & $+1 \cdot 6$ \\
\hline 8 & S & 20 & $1 \cdot 55$ & $66 \cdot 2$ & $3 \cdot 130$ & $3 \cdot 33$ & $9 \cdot 2$ & $10 \cdot 3$ & $+1 \cdot 1$ \\
\hline 9 & S & 17 & $1 \cdot 55$ & $48 \cdot 0$ & 3.040 & $1 \cdot 00$ & $23 \cdot 0$ & $24 \cdot 0$ & $+1 \cdot 0$ \\
\hline 10 & S & 17 & 1.62 & $98 \cdot 0$ & 3.070 & $4 \cdot 75$ & $28 \cdot 0$ & $20 \cdot 0$ & $-8 \cdot 0$ \\
\hline \multicolumn{10}{|c|}{ Epidural analgesia } \\
\hline 11 & $\mathrm{~S}$ & 17 & $1 \cdot 61$ & 67.5 & $3 \cdot 230$ & $4 \cdot 25$ & $15 \cdot 0$ & $36 \cdot 0$ & $+21 \cdot 0$ \\
\hline 12 & $\mathrm{~F}$ & 28 & $1 \cdot 70$ & $50 \cdot 8$ & $3 \cdot 500$ & $4 \cdot 58$ & 12.0 & $22 \cdot 4$ & $+10 \cdot 4$ \\
\hline 13 & F & 28 & 1.64 & $66 \cdot 2$ & $3 \cdot 140$ & $6 \cdot 75$ & $26 \cdot 9$ & 33.8 & +6.9 \\
\hline 14 & $\mathrm{~S}$ & 18 & 1.50 & $52 \cdot 2$ & $3 \cdot 130$ & 3.42 & 35.0 & $36 \cdot 9$ & +1.9 \\
\hline 15 & $\mathrm{~S}$ & 22 & 1.56 & $69 \cdot 1$ & 3.488 & $5 \cdot 25$ & 41.4 & $42 \cdot 1$ & +0.7 \\
\hline 16 & $\mathrm{~S}$ & 29 & 1.59 & 71.5 & 3.830 & $9 \cdot 25$ & $25 \cdot 0$ & $22 \cdot 0$ & $-3 \cdot 0$ \\
\hline 17 & $\mathrm{~F}$ & 22 & 1.63 & $60 \cdot 8$ & $3 \cdot 190$ & 7.00 & $8 \cdot 5$ & $5 \cdot 28$ & $-3 \cdot 2$ \\
\hline 18 & $\mathrm{~S}$ & 26 & 1.60 & $56 \cdot 1$ & 3.650 & $3 \cdot 50$ & $51 \cdot 1$ & $43 \cdot 5$ & -7.6 \\
\hline 19 & $\mathrm{~F}$ & 23 & 1.66 & $85 \cdot 0$ & $3 \cdot 110$ & 11.00 & $25 \cdot 0$ & $16 \cdot 0$ & -9.0 \\
\hline 20 & $\mathrm{~F}$ & 19 & 1.60 & $64 \cdot 5$ & 3.690 & $5 \cdot 50$ & $46 \cdot 0$ & $28 \cdot 0$ & -18.0 \\
\hline
\end{tabular}

S, Spontaneous; F, forceps.

${ }^{a}$ Increment $=$ crowning-full dilatation conen.

(SD 13.5), $U=27, P<0.05$ ], but not in the epidural group [mean $0.0 \mathrm{pg} / \mathrm{ml}$ (SD 11.0]. The forceps delivery rate was higher in the epidural group $(50 \%)$ than in the control group $(10 \%)$ $(P=0 \cdot 14)$. Comparison of the patients having a forceps delivery with those having a spontaneous delivery, irrespective of the method of analgesia (Fig. 1), showed that the level of oxytocin immediately before spontaneous delivery was significantly higher $(U=14, P<0.025)$ than that at forceps delivery. This difference between the spontaneous and forceps delivery groups was not present at levels considered significant in similar comparisons of oxytocin increment $(U=25$, $P>0.05)$ and full dilatation oxytocin $(U=28$, $P>0.05)$. To exclude any interfering effect of forceps delivery on oxytocin levels, particularly at crowning, comparison was confined to those patients who had a spontaneous delivery (nine in the control group and five in the epidural group) and in these patients the trends in oxytocin levels between control and epidural groups were similar to those found before. The median increment was higher in the control group $(6.8 \mathrm{pg} / \mathrm{ml})$ compared with that in the epidural group $(-1 \cdot 2$ $\mathrm{pg} / \mathrm{ml})(U=13, P>0.05$ with smaller numbers $)$ but no difference was seen in absolute levels of oxytocin at full dilatation or crowning. [There were positive correlations in the control group (but not the epidural group) of age with oxytocin levels at crowning $\left(r_{\mathrm{s}}=0.73, P<0.2\right)$ and with the oxytocin increment $\left(r_{\mathrm{S}}=0.84, P<0.01\right)$ that are unexplained.]

\section{Discussion}

We found a significant rise in peripheral plasma oxytocin concentration in normal (control) primigravidae between full dilatation and crowning which confirmed previous reports (Dawood et al. 1978; Leake et al. 1979). Kumaresan et al. (1974) and Gazárek et al. (1976) found no significant change in the second stage but used cross-sectional data. Using serial observations 
Vasicka et al. (1978) found a second stage rise which was attenuated by pudendal, caudal and paracervical block. Sellers et al. (1981) using cross-sectional data found no change but also studied nine women in labour with paired samples. Their timing, however, was less rigid than ours and the methods of analgesia (epidural?) were not recorded.

In contrast with our control subjects, the primigravidae with epidural analgesia in this study showed no consistent or significant increment in oxytocin levels and this relation persisted even in those patients who were delivered normally. These findings suggest that lumbar epidural analgesia which achieves uterine and perineal analgesia blocks or attenuates the normal increase of oxytocin in the second stage of primigravidae in normal labour. We suggest this may at least partly explain the relatively high incidence of forceps delivery in patients with epidural analgesia.

It is well known that the small diameter of autonomic nerve fibres predisposes them to local block and that the pelvic parasympathetic fibres re-enter the spinal cord at its lower end; therefore oxytocin deficiency in association with epidural analgesia can be explained by the local block of a birth reflex of the type described by Ferguson (1941), Fitzpatrick (1961), Dawood et al. (1978) and Leake et al. (1979). The observations of Vasicka et al. (1978) were confirmed for local block but it is interesting that they found no attenuation with epidural analgesia. Altering lumbar epidural technique leads to a considerable variation in effect (Doughty 1969); perineal and uterine analgesia were present in our patients, but a more localized block may have less effect on pelvic autonomic reflexes, or it may be allowed to wear off before delivery. Although factors like these may account for the differences between our results and those found by Vasicka et al. (1978), reduced local anaesthetic tissue levels produced by withholding 'top ups' are likely to continue to block small autonomic nerves for some time after sensation to pain has returned.

Other reasons could be advanced for the observed inhibition of oxytocin release. There may be an associated release of oxytocin and antidiuretic hormone (Berde 1959). Both neurohormones are secreted from separate neurons which are closely approximated in the supraoptic and paraventricular hypothalamic nuclei (Dierickx \& Vandesande 1977). By studying a more stable substance called neurophysin associated with release of these neurohormones, Legros \& Franchimont (1972) showed that release was stimulated by dehydration, exercise and ketosis while fluid load was inhibitory. All patients with epidural analgesia were treated as a usual safety precaution with from 500 to $3000 \mathrm{ml}$ intravenous fluids, while controls did not require intravenous infusion. Although ketacidosis is reduced by epidural analgesia (Pearson \& Davies 1974) none of the study patients were subjected to prolonged labour and none developed severe ketosis or dehydration. These differences seem unlikely to explain the differences in oxytocin secretion we found in our patients.

The fetus at normal delivery has much higher cord blood levels of oxytocin than those found in the mother's peripheral blood (Chard et al. 1971; Dawood et al. 1978; Sellers et al. 1981). It has been suggested that human labour may therefore be controlled by fetal oxytocin release. If this applies to the second stage then depression of fetal central nervous system activity by epidural analgesia (Rosenblatt et al. 1981) might explain the lack of maternal oxytocin increment. The whole subject of fetal oxytocin in labour is hotly debated and has been reviewed recently (Swaab \& Boer 1979). Transport across the placenta and epiphenomena effects due to a preferential fetal sampling site, oxytocinase variability and cross stimulation during fetal neurohormone release (Legros \& Franchimont 1972) are other factors to consider.

Whatever the exact cause, the consequence of delay in the second stage and forceps delivery may be harmful (O'Driscoll et al. 1981). Our observations suggest that the need for forceps associated with epidural analgesia in primigravidae might be reduced by instituting or increasing treatment with oxytocin during the second stage of labour. We have already shown in a controlled study that this can be achieved (Goodfellow \& Studd 1979) and since such treatment was generally applied in the Bristol Maternity Hospital where there are approx. 4500 deliveries annually the overall forceps rate has been reduced significantly from $21.4 \%$ in 1976 to $9.2 \%$ in $1980(P<0.001$, ventouse 0.6 and $0.5 \%$ respectively) with little change in the caesarean section rate $(9 \cdot 8-9 \cdot 1 \%)$. Although the epidural rate has also fallen from 25 to $15 \%$ the 'forceps rate' of primigravidae with epidural analgesia delivered vaginally has been reduced from over 70 to $43 \%$ (ventouse included, breech excluded).

Although the spontaneous delivery rate in 
primigravidae with epidural analgesia has been increased in association with oxytocin supplementation in the second stage of labour it remains to be shown whether the rate in patients without epidural block can be equalled. Fitzpatrick (1961) pointed out that the oxytocin changes in the second stage are much greater than those found after oxytocin induction. Oxytocin doses for induction have increased since then but it is uncertain whether imitation of this natural reflex can be fully achieved with safety. Nevertheless, modest intravenous supplementation of oxytocin during the second stage amounting to $32 \mathrm{~m}$ units/min has proved rewarding and our present study confirms the need for it in epidural treated primigravidae.

\section{Acknowledgments}

We are grateful for the co-operation of colleagues and midwifery staff at Leeds and Bristol Maternity Hospitals, the technical assistance of Mrs H. Searle and the advice of Professor B. Pickering of the Department of Anatomy, Bristol University.

\section{References}

Alvarez, H., Blanco, Y., Panizza, V., Rozada, H. \& Lucas, O. (1965) Effect of electrical stimulation of the presacral nerve on contractility of the human pregnant uterus. Am J Obstet Gynecol 93, 131-135.

Berde, B. (1959) Recent Progress in Oxytocin Research (Thomas, C., Ed.), Springfield, Illinois, USA.

Bristol Maternity Hospital Reports (1976, 1980) Bristol and Weston Health District (Teaching).

Chard, T., Hudson, C. N., Edwards, C. R. W. \& Boyd, N. R. H. (1971) Release of oxytocin and vasopressin by the human fetus during labour. Nature (London) 234, 352-354.

Coch, J. A., Brovetto, J., Cabot, H. M., Fielitz, C. A. \& Caldeyro-Barcia, R. (1965) Oxytocin equivalent activity in the plasma of women in labour and during the puerperium. Am J Obstet Gynecol 91, 10-17.

Dawood, M. Y., Raghavan, K. S., Pociask, C. \& Fuchs, F. (1978) Oxytocin in human pregnancy and parturition. Obstet Gynecol 51, 138-143.

Debackere, M., Peeters, G. \& Tuyttens, N. (1961) Reflex release of an oxytocic hormone by stimulation of genital organs in male and female sheep studied by cross circulation technique. $J$ Endocrinol 22, 321-334.

Dierickx, K. \& Vandesande, F. (1977) Immunocytochemical localisation of the vasopressinergic and the oxytocinergic neurons in the human hypothalamus. Cell Tissue Res 184, 15-27.
Dogterom, J., Van Wimersa Greidanus, Tj. B. \& Swaab, D. F. (1977) Evidence for the release of vasopressin and oxytocin into cerebrospinal fluid: measurements in plasma and CSF of intact and hypophysectomized rats. Neuroendocrinology 24, 108-118.

Dogterom, J., Snijdewint, F. G. M., Pévet, P. \& Swaab, D. F. (1980) Studies on the presence of vasopressin, oxytocin and vasotocin in the pineal gland, subcommisural organ and fetal pituitary gland: failure to demonstrate vasotocin in mammals. $J$ Endocrinol 84, 115-123.

Doughty, A. (1969) Selective epidural analgesia and the forceps rate. Br J Anaesth 41, 1058-1062.

Ferguson, J. K. W. (1941) A study of the motility of the intact uterus at term. Surg Gynecol Obstet 73, 359-366.

Fitzpatrick, R. J. (1961) Blood concentration of oxytocin in labour. J Endocrinol 22, xix.

Gazárek, F., Pohanka, J., Talãs, M., Fingerová, H., Janõuskova, M., Kr̃ikal, Z. \& Hamal, Z. (1976) Plasma oxytocin and oxytocinase levels in third trimester of pregnancy and at labour. Endocrinol Exp (Bratisl) 10, 283-287.

Goodfellow, C. F. \& Studd, C. (1979) The reduction of forceps in primigravidae with epidural analgesia-a controlled trial. Br J Clin Pract 33, 287-288.

Kumaresan, P., Anandarangam, P. B., Dianzon, W. \& Vasicka, A. (1974) Plasma oxytocin levels during human pregnancy and labor as determined by radioimmunoassay. Am J Obstet Gynecol 119, 215 223.

Leake, R. D., Weitzman, R. E., Glatz, T. H. \& Fisher, D. A. (1979) Stimulation of oxytocin secretion in the human. Clin Res 27, 99A.

Legros, J. J. \& Franchimont, P. (1972) Human neurophysine blood levels under normal, experimental and pathological conditions. Clin Endocrinol 1, 99-113.

O'Driscoll, K. \& Meagher, D. (1980) In Active Management of Labour. Clinics in Obstetrics and Gynaecology Supplement I, W. B. Saunders, London.

O'Driscoll, K., Meagher, D., MacDonald, D. \& Geoghegan, F. (1981) Traumatic intracranial haemorrhage in firstborn infants and delivery with obstetric forceps. Br J Obstet Gynaecol 88, 577581.

Paintin, D. B. \& Vincent, F. (1980) Forceps deliveryobstetric outcome. In Outcomes of Obstetric Intervention in Britain Proceedings of a scientific meeting of the Royal College of Obstetricians and Gynaecologists, pp. 17-32.

Pearson, J. F. \& Davies, P. (1974) The effect of continuous lumbar epidural analgesia upon fetal acid base status during the second stage of labour. Br J Obstet Gynaecol 81, 971-974.

Rosenblatt, D. B., Belsey, E. M., Lieberman, B. A., Redshaw, M., Caldwell, J., Notarianni, L., Smith, 
R. L. \& Beard, R. W. (1981) The influence of maternal analgesia on neonatal behaviour. II. Epidural bupivicaine. $\mathrm{Br} J$ Obstet Gynaecol 88, 407-413.

Rotunda Hospital Clinical Report (1979) The Brunswick Press, Dublin.

Sellers, S. M., Hodgson, H. T., Mountford, L. A., Mitchell, M. D., Anderson, A. B. M. \& Turnbull, A. C. (1981) Is oxytocin involved in paturition? $\mathrm{Br}$ J Obstet Gynaecol 88, 725-729.

Swaab, D. F. \& Boer, K. (1979) Function of pituitary hormones in human parturition - a comparison with data in the rat. In Human Parturition (Keirse, M.J.N.C. \& Anderson, A.B.M., Eds), J. Bennebroek Gravenhorst, Boerhaave Series Vol. 15, Leiden University Press, pp. 49-71.

Vasicka, A., Kumaresan, P., Han, G. S. \& Kumaresan, M. (1978) Plasma oxytocin in initiation of labour. Am J Obstet Gynecol 130, 263-273.

Received 17 May 1982

Accepted 5 October 1982 